\title{
Effects of Passive and Active Rest on Physiological Responses and Time Motion Characteristics in Different Small Sided Soccer Games
}

\author{
by \\ Ersan Arslan' ${ }^{1}$ Utku Alemdaroglu², Yusuf Koklu², Tahir Hazir ${ }^{3}$, \\ Surhat Muniroglü, Baris Karakoc ${ }^{5}$
}

\begin{abstract}
The purpose of this study was to investigate the effects of resting regimes on physiological responses and time motion characteristics between bouts during small sided games (SSGs) in young soccer players. Sixteen players (average age $16.87 \pm 0.34$ years; body height $176.69 \pm 3.21 \mathrm{~cm}$; body mass $62.40 \pm 2.59 \mathrm{~kg}$; training experience $3.75 \pm$ 0.44 years) performed four bouts 2-a-side, 3-a-side and 4-a-side games with three minutes active (SSGar: Running at $70 \%$ of HRmax) and passive (SSGpr) rest between bouts at two-day intervals. The heart rate (HR) along with total distance covered in different speed zones - walking (W, 0-6.9 $\mathrm{km} \cdot \mathrm{h}-1$ ), low-intensity running (LIR, 7.0-12.9 km.h-1), moderate-intensity running (MIR, 13.0-17.9 $\mathrm{km} \cdot \mathrm{h}-1)$ and high-intensity running $(H I R,>18 \mathrm{~km} \cdot \mathrm{h}-1)$, were monitored during all SSGs, whereas the rating of perceived exertion (RPE, CR-20) and venous blood lactate (La-) were determined at the end of the last bout of each SSG. The results demonstrated that all SSGpr elicited significantly higher physiological responses compared to SSGar in terms of the RPE and La- $(p<0.05)$. In addition, 2-a-side SSGpr induced significantly lower \%HRmax responses and total distance covered than 2-a-side SSGar $(p<0.05)$. Moreover, the distance covered at HIR was significantly higher in 4-a-side SSGar than 4-side SSGpr. The results of this study indicate that both SSGs with passive and active rest can be used for soccer specific aerobic endurance training. Furthermore, all SSGs with active recovery should be performed in order to increase players and teams' performance capacity for subsequent bouts.
\end{abstract}

Key words: game based training, physiological responses, time-motion characteristics, work rest ratio.

\section{Introduction}

Soccer is characterized as a high-intensity intermittent team sport requiring jumping, shooting, tackling, turning, sprinting, controlling the ball under pressure, running at different speeds, and sliding tackles (Hill-Haas et al., 2011; Stølen et al., 2005). Recent studies have found that soccer players perform $\sim 1200$ acyclical and unpredictable changes in activity (each lasting from 3 to $5 \mathrm{~s}$ ) and cover between $8000 \mathrm{~m}$ and
$14000 \mathrm{~m}$ during a match (Aguiar et al., 2012; Dellal et al., 2011; Koklu et al., 2013). This evidence shows that factors such as technical, tactical and physical skills can affect player's performance. Furthermore, players require welldeveloped aerobic endurance and anaerobic capacity (Little and Williams, 2006). Although most coaches have used running drills without the ball to develop soccer players' aerobic

\footnotetext{
1 - Department of School of Physical Education and Sports, Siirt University, Siirt, Turkey.

2 - Department of Faculty of Sport Sciences, Pamukkale University, Denizli, Turkey.

3 - Department of Faculty of Sport Sciences, Hacettepe University, Ankara, Turkey.

4 - Department of Faculty of Sport Sciences, Ankara University, Ankara, Turkey.

5 - Fenerbahçe SK Trainer, Istanbul, Turkey.
} 
endurance, small-sided games (SSGs) are increasingly thought to be more suitable than traditional interval training for the development of particular physical characteristics required for matches such as technical skills, decision-making ability and aerobic endurance (Little and Williams, 2007). This is because these games involve the actual movement types and patterns used in soccer and they therefore ensure more suitable use of the available training time (Little and Williams, 2006). In addition, research has showed that SSGs could be used for different groups such as professional players (Dellal et al., 2011), amateur players (Clemente et al., 2014), elite youth players (Koklu et al., 2015a), as well as youth players (Clemente et al., 2015) in order to improve both aerobic and anaerobic performance.

Previous studies have shown that various factors affect the level of players' activity during SSGs, such as the number of players and the pitch size (Clemente et al., 2014; Dellal et al., 2011; Randers et al., 2014), inclusion or exclusion of goalkeepers (Gaudino et al., 2014; Koklu et al., 2013), game rules (Clemente et al., 2015; Sampaio et al., 2014), coach encouragement (Rampinini et al., 2007), team formation (Koklu et al., 2012a) and training regime (Hill-Haas et al., 2009; Koklu, 2012b). Therefore, it is thought that these factors result in different heart rates (HR), percentage of maximum HR (\%HRmax), and blood lactate (La-) responses during SSGs (Rampinini et al., 2007). Although these are not the only relevant factors, it is clear that SSGs can be used instead of interval training in order to improve aerobic capacity in soccer players (Iaia et al., 2009). Additionally, the resting regimes between bouts (active or passive) could affect physiological and time motion responses to SSGs.

A few studies have examined the effects of active vs. passive rest on performance in subsequent bouts of interval training. Spierer et al. (2004) found that active rest increased total work in sedentary and moderately trained players in an anaerobic test over four bouts with $5 \mathrm{~min}$ rest in between. In another study, it was found that an active resting regime was more effective than passive rest over repeated performances (Draper et al., 2006). Additionally, Buchheit and Laursen (2013) cited that a beneficial performance effect on subsequent intervals can be expected with long recovery periods ( $\geq 3 \mathrm{~min}$ ) of active rest
(Connolly et al., 2003; Dorado et al., 2004). These studies have shown that an active resting regime between bouts of interval training has a positive effect on performance capacity (Buchheit and Laursen, 2013).

Although some studies (Dupont et al., 2003, 2004) have examined the effects of resting regimes on interval training performance, other studies (Hill-Haas et al., 2009; Koklu, 2012b) interested in the game-based training model have investigated the effects of active and passive resting regimes in SSGs, which resembled interval training. However, only few studies have examined resting regimes in terms of physiological responses and time-motion characteristics with regard to SSGs (Koklu et al., 2015a; McLean et al., 2016). Therefore, the purpose of this study was to investigate the effects of different resting regimes (passive and active) on physiological responses and timemotion characteristics in different SSG formats (2a-side, 3-a-side, and 4-a-side) in youth soccer players.

\section{Methods}

\section{Subjects}

Sixteen soccer players participated in this study voluntarily (age 16.87 \pm 0.34 years; body height $176.69 \pm 3.21 \mathrm{~cm}$; body mass $62.40 \pm 2.59 \mathrm{~kg}$; training experience $3.75 \pm 0.44$ years). All players were members of the same youth team competing in an elite academy league, training for 2 hours 5 days per week in a season. All players were well familiarized with different formats of SSGs and the use of HR monitors and GPS units. The players and their parents were notified of the research procedures, requirements, benefits, and potential risks before providing written informed consent. This study was approved by the Research Ethics Committee of the Ankara University, and was conducted in a manner consistent with the institutional ethical requirements for human experimentation in accordance with the Declaration of Helsinki.

Experimental Design

One week training period served as familiarization to different formats of SSGs and the Yo-Yo Intermittent Recovery Test Level 1 (YIRT1) for the subjects. After this familiarization period, the experiment was conducted over 2 weeks, during which time the players were not 
involved in any other training or matches. On the first day, anthropometric measurements (body mass and body height) were taken for each player; this was followed by the YIRT1, in which the $H_{\text {max }}$ for each player was determined as the highest HR value, and they were ranked from best to worst according to the distance covered in the test. The ranking system worked as follows: players who covered the least distance were given a score of 1 and those who covered the most ground were awarded a score of 5 (Casamichana and Castellano, 2010; Koklu, 2012b). The coach also assessed an overall technical/tactical skill level for each player using a 5-point scale (from 1 "below average" to 5 "outstanding"). The total score for each player was the sum of their technical/tactical skill and YYIRT scores (Casamichana and Castellano, 2010; Koklu, 2012b). In an attempt to avoid skill and fitness mismatches and a consequent imbalance in opposing SSG teams, each SSG team was balanced in terms of the players' skill and fitness rankings (Koklu et al., 2012a). These distance values were then used when establishing SSG teams (Koklu et al., 2013). Each SSG bout was played after a standardized 20 min warm-up consisting of low intensity running, striding, and dynamic stretching. The SSGs involved every player in 4 bouts each under the SSGpr and SSGar conditions (Table 1); they were organized in random order with 2-day intervals in between. Passive rest involved sitting, while active rest involved $70 \%$ of $\mathrm{HR}_{\max }$ running, followed by walking (first $30 \mathrm{~s}$ ). During the SSGs, HR responses and total distance covered in different speed zones were recorded. The rating of perceived exertion (RPE) was determined immediately after the end of the bout of each SSG. In addition, levels of venous blood lactate (La) were also determined with the same 4 lactate analyzers within a minute after the end of the last bout of each SSG, respectively (Taoutaou et al., 1996). The YIRT1 and SSGs were performed on a natural grass pitch at the same time of the day (between 4 and 6 p.m.) to ensure similar chronobiological characteristics (Drust et al., 2005).

\section{Procedures}

\section{Yo-Yo Intermittent Recovery Test 1}

The Yo-Yo Intermittent Recovery Test 1 (YIRT1) consists of repeated $20 \mathrm{~m}$ runs back and forth between the starting, turning, and finishing lines, at a progressively increased speed, which is controlled by audio beeps from a tape recorder. The tape (YO-YO tests, HO + Strom, Denmark) was calibrated prior to every trial and procedures were identical to those previously described by Bangsbo et al. (2008). Each player's HR was measured at $5 \mathrm{~s}$ intervals during the test and stored using HR monitors (Polar S610i, Polar Electro OY, Kempele, Finland). Stored data were transferred to the computer and filtered by dedicated software (Polar Precision Performance SoftwareTM, Finland). During the test, the highest HR measurement was recorded as HRmax (Krustrup et al., 2003).

\section{Small-Sided Games}

The SSG formats used were 2-, 3- and 4-aside games, each involving 4 bouts, with the variables illustrated in Table 1. The SSGs were performed without a goalkeeper or any SSGspecific rules and with the instruction to maintain collective possession of the ball for as long as possible. To minimize interruption when the ball left the field of play, spare balls were kept allround the pitch and four supporting players stood round the edges of the playing area. Verbal encouragement was given by the coaches throughout the games.

\section{Heart Rate Monitoring}

The heart rate (HR) was recorded at $5 \mathrm{~s}$ intervals during the SSG bouts using short-range radio telemetry (SPI ProX; GPSports, Canberra, Australia). Polar S610i HR monitors were also used during the YIRT1 to determine each player's $\mathrm{HR}_{\max }$ expressed as \%HR max so that players could follow individual $70 \% \mathrm{HR}_{\max }$ in between.

\section{Blood Sampling}

Blood lactate samples ( $\left.\mathrm{La}^{-}\right)$were taken within $3 \mathrm{~min}$ after the end of the last bout in line with Taoutaou et al. (1996). The blood samples were taken from the ear lobe and immediately (within $13 \mathrm{~s}$ ) analyzed using a Lactate Plus analyzer (Nova Biomedical, Waltham, MA, USA) which had been previously determined as reliable $(r=0.99, p<0.05)$ and valid for evaluating players' blood lactate samples (Hart et al., 2013; Tanner et al., 2010).

\section{Rating of Perceived Exertion}

A perceived exertion rating scale (RPE) was presented to each player immediately after each bout of the SSGs. All players were informed about, and familiarized with the CR-20 scale 
before the SSGs. This scale had been previously used as an indicator of training intensity in intermittent tasks of SSG (Coutts et al., 2009).

\section{Time-motion Characteristics}

Players' movements during the SSGs were recorded using portable global positioning system (GPS) units (SPI ProX; GPSports, Canberra, Australia) and distances were calculated by dedicated software (Team AMS, GPSports, Canberra, Australia). Physiological responses and time motion characteristics were monitored during the SSGs. The GPS unit was placed into a harness that positioned the device between each player's shoulder blades; they were worn by every player involved in SSGs. The distance travelled was recorded at $15 \mathrm{~Hz}$. The 1, 5, $10 \mathrm{~Hz}$ GPS technology had been previously determined as reliable and valid for monitoring players' high-intensity and sprinting activities in soccer (Jennings et al., 2010). The accuracy and reliability of SPI ProX technology for use in team sports or movement patterns had been previously determined. This GPS-based system presented a coefficient of variation of $0.14 \%$ to $3.73 \%$ for distance and $4.22 \%$ to $9.52 \%$ for speed. Furthermore, acceptable reliability of this device had been measured for distance $0.34 \%$ to $3.81 \%$; and speed $3.19 \%$ to $6.95 \%$ (Koklu et al., 2015b). For data analysis purposes, 4 speed zones were selected in line with previous studies: walking (W, 0-6.9 $\mathrm{km} \cdot \mathrm{h}^{-1}$ ), low-intensity running (LIR, 7.0$12.9 \mathrm{~km} \cdot \mathrm{h}^{-1}$ ), moderate-intensity running (MIR, 13.0-17.9 $\mathrm{km} \cdot \mathrm{h}^{-1}$ ) and high-intensity running (HIR, $>18 \mathrm{~km} \cdot \mathrm{h}^{-1}$ ) (Casamichana and Castellano, 2010; Hill-Haas et al., 2010).

\section{Statistical analysis}

The data are reported as means and standard deviations. Before using parametric tests, the assumption of normality was verified using the Shapiro-Wilk test. A paired t-test was performed on each dependent variable, including $\mathrm{HR}$, \%HRmax, level of La, RPE and time-motion characteristics, to compare differences between the SSGpr and SSGar conditions for all games. The level of significance was set at $p<0.05$. Effect sizes (ES-Cohen's d) were also calculated to determine the practical difference between all SSGs with active and passive rest. ES values of $0.20-0.49,0.50-0.79$, and 0.8 and above were considered to represent small, medium, and large differences, respectively (Cohen, 1988). Also, the
95\% Confidence Interval (95\% CI) was calculated for the difference between mean values for each of the estimated variables. Inter-individual variability in $\mathrm{HR}, \% \mathrm{HR}_{\max }, \mathrm{La}-\mathrm{RPE}$ and timemotion characteristics between the SSGar and SSGpr conditions was quantified using the coefficient of variation $(\mathrm{CV})$.

\section{Results}

Figure 1 shows the subjects' average $\% \mathrm{HR}_{\max }, \mathrm{La}^{-}$and $\mathrm{RPE}$ responses during the 2-aside, 3-a-side, and 4-a-side formats under SSGar and SSGpr conditions. As the table indicates, there were significant differences between SSGar and SSGpr in terms of $\mathrm{La}^{-}$and RPE responses in all SSG formats. Two-a-side, 3-a-side and 4-a-side SSGar formats induced significantly lower $\mathrm{La}^{-}$ responses than 2-a-side games played under SSGpr conditions $(\mathrm{t}=3.292 ; p<0.05$; medium effect: $0.64 ; 95 \%$ CI: .80 to -4.03$), 3$-a-side $(\mathrm{t}=2.632$; $p<0.05$; small effect: $0.49 ; 95 \%$ CI: .31 to 3.47$)$ and 4-a-side SSGpr $(\mathrm{t}=3.138 ; p<0.05$; medium effect: 0.54; 95\% CI: .59 to 3.07). In addition, RPE responses in 2-a-side, 3-a-side, and 4-a-side SSGpr were significantly higher than those in 2-a-side $(\mathrm{t}$ $=7.907 ; p<0.05$; large effect: .91; 95\% CI: 1.08 to 1.92), 3-a-side $(\mathrm{t}=7.907 ; p<0.05$; large effect: .81; $95 \%$ CI: .82 to 1.43$)$ and 4 -a-side ( $\mathrm{t}=7.907 ; p<0.05$; medium effect: $0.57 ; 95 \%$ CI: 2.9 to 1.08 ) formats of SSGar. Moreover, 2-a-side SSGar formats showed significantly lower \%HRmax $(t=3.530 ; p<0.05$; small effect: $0.38 ; 95 \%$ CI: .34 to 1.45 ) responses than 2-a-side games played under SSGpr conditions.

Table 2 also resents average distance covered at various speeds in all playing formats and both conditions: walking $\left(0-6.9 \mathrm{~km} \cdot \mathrm{h}^{-1}\right)$, lowintensity running $\left(7.0-12.9 \mathrm{~km} \cdot \mathrm{h}^{-1}\right)$, moderateintensity running (13.0-17.9 $\left.\mathrm{km} \cdot \mathrm{h}^{-1}\right)$ and highintensity running $\left(>18 \mathrm{~km} \cdot \mathrm{h}^{-1}\right)$. It also provides information on the mean total distance covered. The study results indicate that 2-aside SSGpr resulted in significantly lower total distance covered compared to 2-a-side SSGar $(\mathrm{t}=3.295 ; p<$ 0.05; medium effect: .53; 95\% CI: -113.03 to 15.31 ). In addition, 4-a-side SSGar showed significantly greater distance covered at HIR $(\mathrm{t}=9.087 ; \mathrm{p}<0.05$; large effect: .85; 95\% CI: $-50.19,-3.66)$ and lower at walking $(\mathrm{t}=4.616 ; p<0.05$; medium effect: .61; $95 \%$ CI: $30.65,128.60)$ compared to 4 -side SSGpr. 


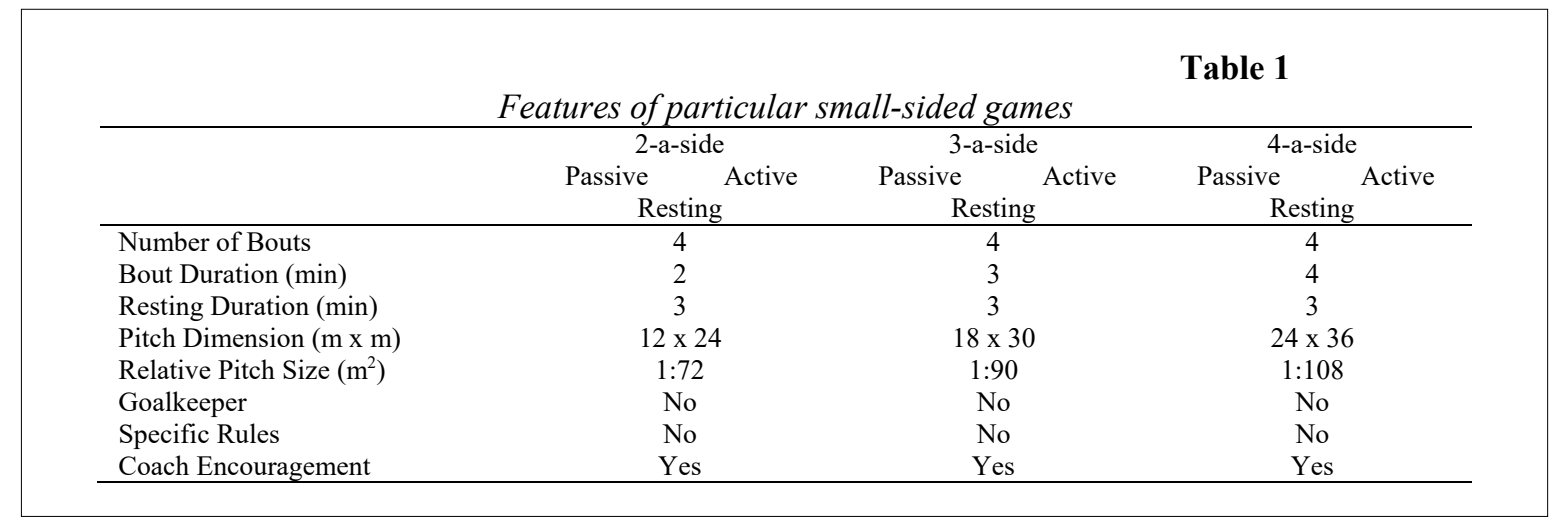

\begin{tabular}{|c|c|c|c|c|c|c|c|c|c|}
\hline \multicolumn{10}{|c|}{$\begin{array}{c}\text { Table } 2 \\
\text { Physiological responses of youth soccer players to SSGpr and SSGar conditions }\end{array}$} \\
\hline \multirow{2}{*}{\multicolumn{3}{|c|}{ Variables }} & \multicolumn{2}{|c|}{ SSGar } & \multicolumn{2}{|c|}{ SSGpr } & \multirow[b]{2}{*}{$\begin{array}{c}\text { Mean } \\
\text { Difference }\end{array}$} & \multirow[b]{2}{*}{$\% 95 \mathrm{CI}$} & \multirow[b]{2}{*}{ ES } \\
\hline & & & Mean \pm SD & $\begin{array}{l}\text { CV } \\
(\%)\end{array}$ & Mean \pm SD & $\begin{array}{l}\mathrm{CV} \\
(\%)\end{array}$ & & & \\
\hline \multirow{12}{*}{ 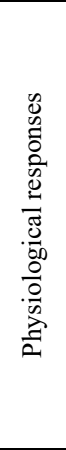 } & \multirow{7}{*}{ 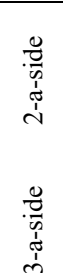 } & HR (beat $\cdot \min ^{-1}$ ) & $171.6 \pm 1.3^{*}$ & 0.73 & $173.3 \pm 1.4$ & 0.83 & -1.75 & $0.7,2.8$ & 0.54 \\
\hline & & $\% \mathrm{HR}_{\max }$ & $88.0 \pm 1.1^{*}$ & 1.27 & $88.9 \pm 1.0$ & 1.16 & -0.9 & $0.3,1.4$ & 0.38 \\
\hline & & $\mathrm{La}^{-}\left(\mathrm{mmol} \cdot \mathrm{L}^{-1}\right)$ & $7.8 \pm 1.0^{*}$ & 13.25 & $10.3 \pm 1.8$ & 17.35 & -2.41 & $0.8,4.0$ & 0.64 \\
\hline & & RPE (CR-20) & $13.2 \pm 0.4^{*}$ & 3.12 & $15.1 \pm 0.5$ & 3.31 & -1.96 & $1.1,1.9$ & 0.91 \\
\hline & & HR $\left(\right.$ beat $\cdot \min ^{-1}$ ) & $169.9 \pm 3.2$ & 1.90 & $170.2 \pm 3.3$ & 1.97 & -0.31 & $-2.5,3.1$ & 0.05 \\
\hline & & $\% \mathrm{HR}_{\max }$ & $87.2 \pm 2.2$ & 2.56 & $87.3 \pm 1.5$ & 1.73 & -0.15 & $-1.3,1.6$ & 0.04 \\
\hline & & $\mathrm{La}^{-}\left(\mathrm{mmol} \cdot \mathrm{L}^{-1}\right)$ & $6.9 \pm 1.2^{*}$ & 15.83 & $8.8 \pm 2.1$ & 23.50 & -1.9 & $0.3,3.5$ & 0.49 \\
\hline & \multirow{5}{*}{ 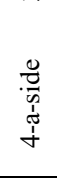 } & RPE (CR-20) & $13.0 \pm 0.4^{*}$ & 3.30 & $14.2 \pm 0.4$ & 2.68 & -1.12 & $0.8,1.4$ & 0.81 \\
\hline & & HR (beat $\left.\cdot \min ^{-1}\right)$ & $168.3 \pm 2.3$ & 1.37 & $168.4 \pm 2.4$ & 1.43 & -0.1 & $0.8,-1.8$ & 0.02 \\
\hline & & $\% \mathrm{HR}_{\max }$ & $86.4 \pm 1.6$ & 1.89 & $86.5 \pm 1.2$ & 1.42 & -0.05 & $-0.8,0.9$ & 0.02 \\
\hline & & $\mathrm{La}^{-}\left(\mathrm{mmol} \cdot \mathrm{L}^{-1}\right)$ & $5.9 \pm 1.6^{*}$ & 27.72 & $7.7 \pm 1.2$ & 15.69 & -1.83 & $0.6,3.1$ & 0.54 \\
\hline & & RPE (CR-20) & $12.3 \pm 0.5^{*}$ & 4.05 & $13.0 \pm 0.5$ & 3.68 & -0.69 & $0.3,1.1$ & 0.57 \\
\hline \multicolumn{10}{|c|}{$\begin{array}{l}\text { HR: Heart Rate; \%HR } \text { max }_{\text {: Percentage of maximum heart rate; La : Blood lactate; }} \\
\text { RPE: Rating of perceived exertion; SSGpr: Small-sided game with passive rest; } \\
\text { SSGar: Small-sided game with active rest; CV: Coefficient of variation; } \\
\text { CI: 95\% Confidence Interval (95\% CI was estimated for the difference between two means), } \\
\text { ES: Effect Size (Absolute value); *Significant difference from SSGpr. } p<0.05 .\end{array}$} \\
\hline
\end{tabular}

\begin{tabular}{|c|c|c|c|c|c|c|c|c|}
\hline & \multirow[b]{3}{*}{ Variables } & \multicolumn{7}{|c|}{$\begin{array}{c}\text { Table } 3 \\
\text { ime-motion characteristics of youth soccer players for SSGpr and SSGar }\end{array}$} \\
\hline & & \multicolumn{2}{|c|}{ SSGar } & \multicolumn{2}{|c|}{ SSGpr } & \multirow{2}{*}{$\begin{array}{c}\text { Mean } \\
\text { Difference }\end{array}$} & \multirow[b]{2}{*}{$\% 95 \mathrm{CI}$} & \multirow[b]{2}{*}{ ES } \\
\hline & & $\begin{array}{c}\text { Mean } \pm \text { SD } \\
(\mathrm{m})\end{array}$ & CV $(\%)$ & $\begin{array}{l}\text { Mean } \pm \text { SD } \\
(\mathrm{m})\end{array}$ & $\begin{array}{l}\mathrm{CV} \\
(\%) \\
\end{array}$ & & & \\
\hline \multirow{5}{*}{ 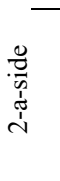 } & $0-6.9 \mathrm{~km} \cdot \mathrm{h}^{-1}$ & $254.6 \pm 27.5$ & 10.82 & $259.6 \pm 31.2$ & 12.01 & -5.03 & $-21.7,31.8$ & 0.33 \\
\hline & $7-12.9 \mathrm{~km} \cdot \mathrm{h}^{-1}$ & $652.9 \pm 40.0$ & 6.13 & $611.0 \pm 56.3$ & 9.21 & 41.94 & $-87,2,3.3$ & 0.40 \\
\hline & $13-17.9 \mathrm{~km} \cdot \mathrm{h}^{-1}$ & $197.2 \pm 32.6$ & 16.54 & $177.4 \pm 49.2$ & 27.75 & 19.80 & $-61.4,21.8$ & 0.21 \\
\hline & $>18 \mathrm{~km} \cdot \mathrm{h}^{-1}$ & $29.0 \pm 23.6$ & 81.10 & $23.0 \pm 21.2$ & 92.30 & 6.06 & $-26.0,13.9$ & 0.15 \\
\hline & $\mathrm{Td}$ & $1134.4 \pm 34.7 *$ & 3.07 & $1070.2 \pm 63.4$ & 5.92 & 64.18 & $-113.0,-15.3$ & 0.53 \\
\hline \multirow{5}{*}{ 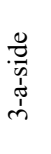 } & $0-6.9 \mathrm{~km} \cdot \mathrm{h}^{-1}$ & $344.7 \pm 73.3$ & 21.26 & $360.9 \pm 67.0$ & 18.57 & -16.22 & $-36.1,68.6$ & 0.11 \\
\hline & $7-12.9 \mathrm{~km} \cdot \mathrm{h}^{-1}$ & $1046.8 \pm 133.9$ & 12.78 & $1008.4 \pm 140.9$ & 13.96 & -38.37 & $-138.7,61.9$ & 0.15 \\
\hline & $13-17.9 \mathrm{~km} \cdot \mathrm{h}^{-1}$ & $293.7 \pm 74.7$ & 25.43 & $260.8 \pm 56.0$ & 21.48 & 32.34 & $-92.0,26.1$ & 0.59 \\
\hline & $>18 \mathrm{~km} \cdot \mathrm{h}^{-1}$ & $47.3 \pm 24.3$ & 51.43 & $42.1 \pm 19.1$ & 45.42 & 5.24 & $-25.2,14.8$ & 0.07 \\
\hline & $\mathrm{Td}$ & $1735.2 \pm 107.2$ & 6.18 & $1681.3 \pm 103.7$ & 6.17 & 53.84 & $-145.8,38.1$ & 0.24 \\
\hline \multirow{5}{*}{ 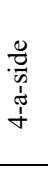 } & $0-6.9 \mathrm{~km} \cdot \mathrm{h}^{-1}$ & $393.7 \pm 54.4^{*}$ & 13.81 & $473.4 \pm 80.8$ & 17.06 & -79.64 & $30.6,128.6$ & 0.61 \\
\hline & $7-12.9 \mathrm{~km} \cdot \mathrm{h}^{-1}$ & $1442.9 \pm 45.4$ & 3.14 & $1344.6 \pm 151.08$ & 11.22 & 98.24 & $-215.3,18.8$ & 0.05 \\
\hline & $13-17.9 \mathrm{~km} \cdot \mathrm{h}^{-1}$ & $382.8 \pm 20.1$ & 5.24 & $335.2 \pm 42.58$ & 12.68 & 47.61 & $-100.2,5.0$ & 0.57 \\
\hline & $>18 \mathrm{~km} \cdot \mathrm{h}^{-1}$ & $121.9 \pm 23.7^{*}$ & 19.43 & $94.9 \pm 37.48$ & 39.39 & 26.9 & $-50.2,-3.7$ & 0.85 \\
\hline & $\mathrm{Td}$ & $2342.9 \pm 27.0$ & 1.15 & $2257.8 \pm 112.3$ & 4.97 & 85.15 & $-176.9,6.6$ & 0.19 \\
\hline & $\begin{array}{r}\text { SSGpr: } S r \\
T d: 1 \\
(95 \% C I w c\end{array}$ & $\begin{array}{r}\text { sided game } \\
\text { distances; } C \\
\text { timated for } t \\
{ }^{*} \mathrm{Si}\end{array}$ & $\begin{array}{l}\text { passiv } \\
\text { Coeffict } \\
\text { ifferen } \\
\text { icant d }\end{array}$ & $\begin{array}{l}\text { sting; SSGar: } \\
\text { of variation; } 9 \\
\text { etween two me } \\
\text { ence from } S S C\end{array}$ & $\begin{array}{l}\text { all-sic } \\
\text { oCI: } 9 \\
\text { s); ES } \\
. p<\end{array}$ & $\begin{array}{l}\text { game wit } \\
\text { o Confider } \\
\text { Effect Size }\end{array}$ & $\begin{array}{l}\text { active restin } \\
\text { Interval } \\
\text { bsolute valu }\end{array}$ & \\
\hline
\end{tabular}



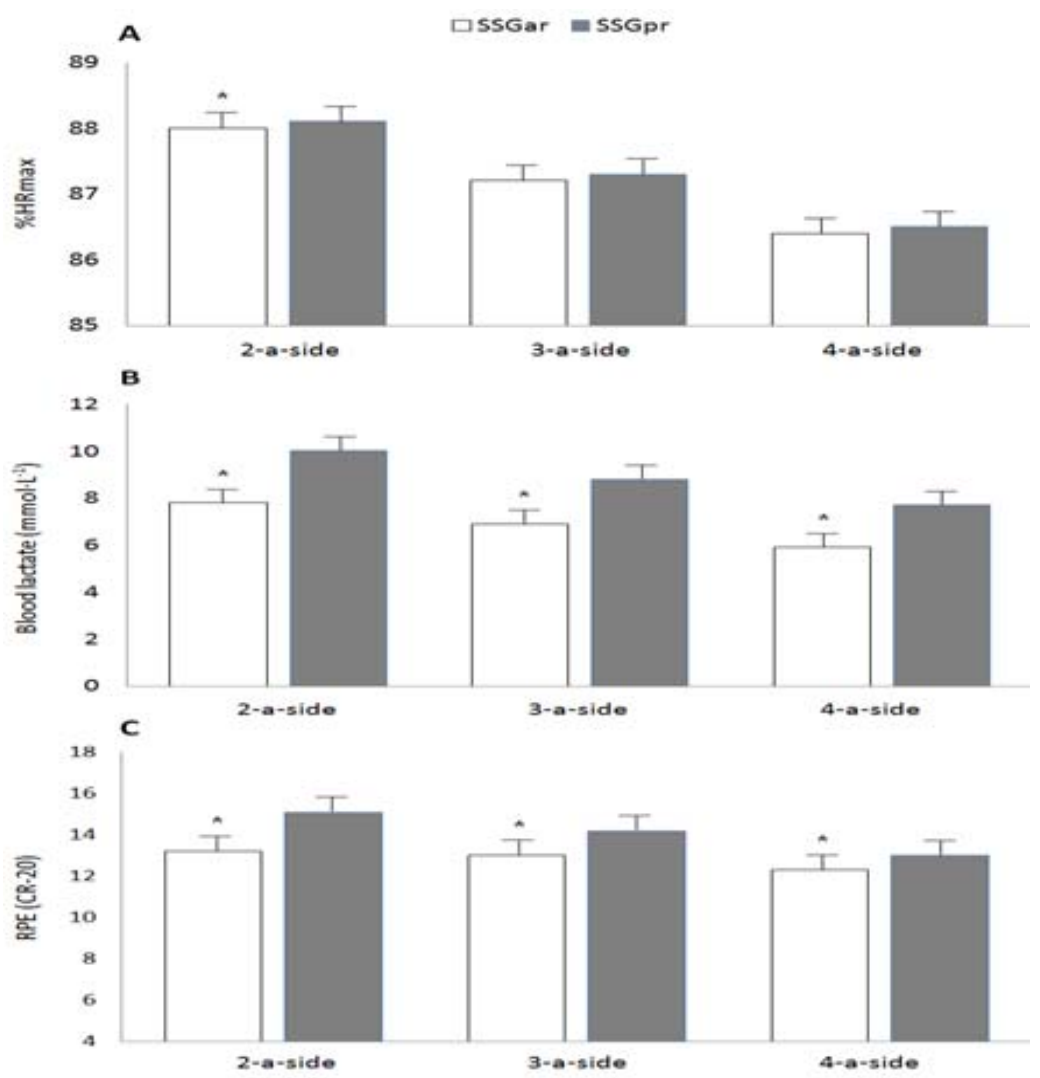

Figure1A-C:

Physiological responses of young soccer players to SSGpr and SSGar conditions

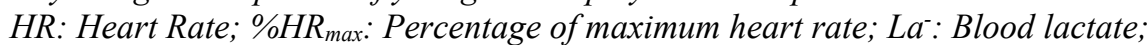
RPE: Rating of perceived exertion; SSGpr: Small-sided game with passive resting; SSGar: Small-sided game with active resting, *Significant difference between SSGpr to SSGar. $p<0.05$.

\section{Discussion}

The purpose of this study was to investigate the effects of resting regimes (passive and active) on physiological responses and timemotion characteristics in different small sided soccer games in youth soccer players. It has been suggested that a combination of HR, RPE and Laconcentration monitoring is the best way to assess internal exercise intensity in SSGs (Coutts et al., 2009). The main findings of the present study are that La- and RPE responses were significantly higher in the passive resting regime and players covered greater total distance in SSGs involving active rest. Additionally, resting regimes had an effect on \%HRmax response and youth soccer players showed significantly lower \%HRmax response only in 2- a-side game format with the active resting regime (Table 2). During the subsequent high intensity exercise, accumulation of La- and muscle metabolic recovery increase (Buchheit and Laursen, 2013). Active rest periods in SSGs allow to remove a part of La- produced and $\mathrm{PCr}$ resynthesis; furthermore, they contribute to anaerobic system engagement during the following effort (Dupont et al., 2004; Spencer et 
al., 2006). Recovery time of PCr stores after a high intensity exercise bout follows a two-phase time course namely fast and slow components (Dupont et al., 2003). Moreover, PCr resynthesis is crucial for the fast component of high intensity exercise (Koklu et al., 2015a). Therefore, our results indicate that using active rest periods in SSGs allows to increase the total load by performing a greater number of bouts or increasing their duration.

In this study, exercise intensity was determined by monitoring HR, \%HRmax, La- and RPE levels during the SSGs. This study found that average \%HRmax responses to SSGs ranged from 86.4 to $88 \%$. Similarly Aguiar et al. (2012) reported that \%HR responses ranged between 88 and $91 \%$ for 2-a-side games, 87 and $90 \%$ for 3-a-side and 85 and $90 \%$ for 4 -a-side SSGs; it can therefore be seen that our findings are similar to those of previous studies. Although HR monitoring is a very common and easy method of measuring intensity of exercise, it has some limitations especially in games with short duration and high intensity (Casamichana et al., 2013; Little and Williams, 2007), thus, different measures should be used in combination with HR, such as blood lactate which is a marker of intensity of anaerobic glycolysis (Casamichana et al., 2013; Coutts et al., 2009; Russell et al., 2011). Average La- responses to SSGs ranged from 5.8 to $10.3 \mathrm{mmol} \cdot \mathrm{L}-1$ in the present study. These values are similar to those found in previous studies of SSGs (Koklu et al., 2013; Little and Williams, 2007; Rampinini et al., 2007). Another tool for monitoring internal loads is the RPE, which is considered to be a viable method for tracking internal loads using low cost, easily accessible procedures to ascertain individuals' global perception of training effort; many studies have reported correlations between RPE measures and HR (Casamichana et al., 2013; Coutts et al., 2009; Impellizzeri et al., 2004).

HRmax, La- and RPE responses in SSGar were found to be lower than those in SSGpr (mean RPE responses of all SSGs ranged from 12.3-15.1; Table 2). These values are similar to those found in previous studies (Little and Williams, 2007; Sampaio et al., 2007). The present study also revealed that large CVs were observed in La- (ranging from 13.25 to $27.72 \%$ ) in RPE responses (ranging from 2.68 to $4.05 \%$ ) for all SSG. These results demonstrated that large differences existed between players with respect to La- and RPE responses during SSGs. These findings revealed inter-player variability when using SSGs as a training stimulus in terms of RPE and Laresponses. In contrast, there were low $\mathrm{CVs}$ in HRmax responses (ranging from 0.73 to $1.97 \%$ ) in $\%$ HRmax responses (ranging from 1.16 to $2.56 \%$ ) in all SSGs. These results showed that players' \%HRmax responses were homogeneous during both the SSGar and SSGpr. The present study also found that $\mathrm{La}$ and RPE responses were significantly higher in SSGpr compared to SSGar. In addition, players had significantly lower \%HRmax response in SSGar only in 2-a-side game format compared to SSGpr.

Changes in HR responses are not sudden in anaerobic drills (Achten and Jeukendrup, 2003). Therefore, HR and energy expenditure become nonlinear and average HR responses measured may be underestimated during games with high intensity and short duration (Little and Williams, 2007). Aroso et al. (2004) reported that altering game duration in intense condition caused increased blood lactate levels without concomitant HR responses. Therefore, the active resting regime enhances blood lactate removal in comparison with the passive resting regime. Passive rest seems to be more suitable than active rest when the rest interval is less than $2-3 \mathrm{~min}$ in duration in long high intensity interval training (HIIT) (Buchheit and Laursen, 2013). On the other hand, active rest is advisable if duration of the rest interval is at least 3-4 min to allow players to reach the desired intensity during the following interval. According to our results, although active rest elicited lower La- and RPE response in players, they managed to perform better in terms of some time-motion characteristics in the active regime. Considering the importance of active rest in SSGs, recent studies have found that technical and tactical variables may significantly affect players' physiological responses and time motion characteristics in small sided games (Castelão et al., 2014; Owen et al., 2014; Vilar et al., 2014). Therefore, the resting regime is an important factor which should not be disregarded.

Determination of external loads in SSGs is as important as determination of physiological response to soccer drills. Nowadays, different technological devices such as GPS devices offer a highly practical way of monitoring players' 
movements during training and SSGs (Hartwig et al., 2011). Owing to these devices, in our study we were able to show that resting regimes constituted a factor which had an effect on the external load of SSGs. We also found that players covered greater total distance in 2-, 3- and 4-a-side games with active rest when compared to passive resting regimes (1134.39 vs. $1070.21 \mathrm{~m} ; 1735.16$ vs. 1681.32 m; 2342.93 vs. $2257.78 \mathrm{~m}$, respectively; Table 3). In addition to physiological responses, distances covered by players at various speeds are also generally considered in order to determine the exercise intensity experienced during SSGs (HillHaas et al., 2011). Many studies have investigated the external load to determine the exercise intensity during various SSGs (Casamichana and Castellano, 2010; Casamichana et al., 2013; HillHaas et al., 2010; Koklu et al., 2012a, 2013). It can be said that the distance covered at HIR reflects the physiological response of the SSGs, instead of total distance covered by players. Therefore, external and internal loads should be assessed together in order to evaluate the intensity of SSGs.

\section{Conclusion}

The results of this study suggest that both SSGpr and SSGar could be used for soccer specific aerobic endurance training. In addition, SSGs with active rest had effect on La- and RPE responses in all SSGs. Time-motion characteristics supported these physiological responses. Our results also indicate that using active rest periods in SSGs allows to increase the total load by performing a greater number of bouts or increasing their duration. Also, higher La- and RPE responses could negatively affect technical variables in SSGpr. Therefore, the effect of resting regimes on technical variables should be examined in further studies. According to our results, coaches and sport scientists should take into account resting regimes when planning SSGs. Furthermore, all SSGs with active recovery should be performed in order to increase players and teams' performance capacity for subsequent bouts.

\section{Acknowledgements}

The author would like to thank all the players for their time and effort during the games.

\section{References}

Achten J, Jeukendrup AE. Heart rate monitoring: Applications and limitations. Sports Med, 2003; 33(7): 517538

Aguiar M, Botelho G, Lago C, Maças V, Sampaio J. A review on the effects of soccer small-sided games. J Hum Kinet, 2012; 33: 103-113

Aroso J, Rebelo AN, Gomes-Pereira J. Physiological impact of selected game-related exercises. J Sports Sci, 2004; 22: 522

Bangsbo J, Iaia FM, Krustrup P. The Yo-Yo intermittent recovery test. Sports Med, 2008; 38(1), 37-51

Buchheit M, Laursen PB. High-intensity interval training, solutions to the programming puzzle. Sports Med, 2013; 43(5): 313-338

Casamichana D, Castellano J. Time-motion, heart rate, perceptual and motor behaviour demands in smallsides soccer games: Effects of pitch size. J Sports Sci, 2010; 28(14): 1615-1623

Casamichana D, Castellano J, Calleja-Gonzalez J, San Román J, Castagna C. Relationship between indicators of training load in soccer players. J Strength Cond Res, 2013; 27(2): 369-374

Castelão D, Garganta J, Santos R, Teoldo I. Comparison of tactical behavior and performance of youth soccer players in 3v3 and 5v5 small-sided games. Int J Per Anal Sport, 2014; 14(3): 801-813

Clemente FM, Wong DP, Martins FML, Mendes RS. Acute effects of the number of players and scoring method on physiological, physical, and technical performance in small-sided soccer games. Res Sports Med, 2014; 22(4): 380-397

Clemente FM, Wong DP, Martins FML, Mendes, R. Differences in U14 football players' performance between different small-sided conditioned games. RICYDE. Revista Internacional de Ciencias del Deporte, 
2015; 11(42): 376-386

Cohen J. Statistical Power Analysis for the Behavioral Sciences. Hillsdale, NJ: Erlbaum Associates; 1988

Connolly DA, Brennan KM, Lauzon CD. Effects of active versus passive recovery on power output during repeated bouts of short term, high intensity exercise. J Sports Sci Med, 2003; 2(2): 47-51

Coutts AJ, Rampinini E, Marcora SM, Castagna C, Impellizzeri FM. Heart rate and blood lactate correlates of perceived exertion during small-sided soccer games. J Sci Med Sport, 2009; 12(1): 79-84

Dellal A, Hill-Haas S, Lago-Penas C, Chamari K. Small-sided games in soccer: amateur vs. professional players' physiological responses, physical, and technical activities. J Strength Cond Res, 2011; 25(9): 2371-2381

Dorado C, Sanchis-Moysi J, Calbet JA. Effects of recovery mode on performance, $\mathrm{O}_{2}$ uptake, and $\mathrm{O} 2$ deficit during high-intensity intermittent exercise. Can J Appl Physiol, 2004; 29(3): 227-244

Draper N, Bird EL, Coleman I, Hodgson C. Effects of active recovery on lactate concentration, heart rate and RPE in climbing. J Sports Sci Med, 2006; 5(1): 97-105

Drust B, Waterhouse J, Atkinson G, Edwards B, Reilly T. Circadian rhythms in sports performance-an update. Chronobiol Int, 2005; 22(1): 21-44

Dupont G, Blondel N, Berthoin S. Performance for short intermittent runs: active recovery vs. passive recovery. Eur J Appl Physiol, 2003; 89(6): 548-554

Dupont G, Moalla W, Guinhouya C, Ahmaidi S, Berthoin S. Passive versus active recovery during highintensity intermittent exercises. Med Sci Sports Exerc, 2004; 36(2): 302-308

Gaudino P, Alberti G, Iaia FM. Estimated metabolic and mechanical demands during different small-sided games in elite soccer players. Hum Mov Sci, 2014; 36: 123-133

Hart S, Drevets K, Alford M, Salacinski A, Hunt BE. A method-comparison study regarding the validity and reliability of the Lactate Plus analyzer. BMJ open, 2014; 3(2): 1-7

Hartwig TB, Naughton G, Searl J. Motion analyses of adolescent rugby union players: a comparison of training and game demands. J Strength Cond Res, 2011; 25(4): 966-972

Hill-Haas SV, Coutts AJ, Dawson BT, Rowsell GJ. Time-motion characteristics and physiological responses of small-sided games in elite youth players: the influence of player number and rule changes. $J$ Strength Cond Res, 2010; 24(8): 2149-2156

Hill-Haas SV, Dawson BT, Coutts AJ, Rowsell GJ. Physiological responses and time-motion characteristics of various small-sided soccer games in youth players. J Sports Sci, 2009; 27(1): 1-8

Hill-Haas SV, Dawson B, Impellizzeri FM, Coutts AJ. Physiology of small-sided games training in football. Sports Med, 2011; 41(3): 199-220

Iaia FM, Rampinini E, Bangsbo J. High-intensity training in football. Int J Sports Physiol Perform, 2009; 4(3): 291-306

Impellizzeri FM, Rampinini E, Coutts AJ, Sassi A, Marcora SM. Use of RPE-based training load in soccer. Med Sci Sports Exerc, 2004; 36: 1042-1047

Jennings D, Cormack S, Coutts AJ, Boyd L, Aughey RJ. The validity and reliability of GPS units for measuring distance in team sport specific running patterns. Int J Sports Physiol Perform, 2010; 5(3): 328341

Koklu Y. A comparison of physiological responses to various intermittent and continuous small-sided games in young soccer players. J Hum Kinet, 2012b; 31: 89-96

Koklu Y, Alemdaroglu U, Delall A, Wong DP. Effect of different recovery durations between bouts in 3-aside games on youth soccer players' physiological responses and technical activities. J Sports Med Phys Fitness, 2015a; 55: 430-438

Koklu Y, Arslan Y, Alemdaroglu U, Duffield R. The accuracy and reliability of spi prox global positioning system devices for measuring movement demands of team sports. J Sports Med Phys Fitness, 2015b; 55(5): 471-477

Koklu Y, Ersoz G, Alemdaroglu U, Asci A, Ozkan A. Physiological responses and time-motion 
characteristics of 4-a-side small-sided game in young soccer players: The influence of different team formation methods. J Strength Cond Res, 2012a; 26(11): 3118-3123

Koklu Y, Sert O, Alemdaroglu U, Arslan Y. Comparison of the physiological responses and time motion characteristics of young soccer players in small sided games: The effect of goalkeeper. J Strength Cond Res, 2013; 29(4): 964-971

Krustrup P, Mohr M, Amstrup T, Rysgaard T, Johansen J, Steensberg A, Bangsbo J. The yo-yo intermittent recovery test: physiological response, reliability, and validity. Med Sci Sports Exerc, 2003; 35(4): 697-705

Little T, Williams AG. Suitability of soccer training drills for endurance training. J Strength Cond Res, 2006; 20(2): 316-319

Little T, Williams AG. Measures of exercise intensity during soccer training drills with professional soccer players. J Strength Cond Res, 2007; 21(2): 367-371

McLean S, Kerhervé H, Lovell GP, Gorman AD, Solomon C. The effect of recovery duration on Vastus Lateralis oxygenation, heart rate, perceived exertion and time motion descriptors during small sided football games. PloS one, 2016; 11(2): e0150201

Owen AL, Wong DP, Paul D, Dellal A. Physical and technical comparisons between various-sided games within professional soccer. Int J Sports Med, 2014; 35(4): 286-92

Rampinini E, Impellizzeri FM, Castagna C, Abt G, Chamari K, Sassi A, Marcora SM. Factors influencing physiological responses to small-sided soccer games. J Sports Sci, 2007; 25(6): 659-666

Randers MB, Nielsen JJ, Bangsbo J, Krustrup P. Physiological response and activity profile in recreational small-sided football: No effect of the number of players. Scand J Med Sci Sports, 2014; 24(S1): 130-137

Russell M, Benton D, Kingsley M. The effects of fatigue on soccer skills performed during a soccer match simulation. Int J Sports Physiol Perform, 2011; 6(2): 221-233

Sampaio JE, Lago C, Gonçalves B, Maçãs VM, Leite N. Effects of pacing, status and unbalance in time motion variables, heart rate and tactical behavior when playing 5-a-side football small-sided games. Int $J$ Sports Physiol Perform, 2014; 17(2): 229-233

Sampaio J, Garcia G, Macas V, Ibanez J, Abrantes C, Caixinha P. Heart rate and perceptual responses to $2 \times 2$ and 3×3 small-sided youth soccer games. J Sports Sci Med, 2007; 6(10): 121-122

Spencer M, Bishop D, Dawson B, Goodman C, Duffield R. Metabolism and performance in repeated cycle sprints: active versus passive recovery. Med Sci Sports Exerc, 2006; 38(8): 1492-1499

Spierer DK, Goldsmith R, Baran DA, Hryniewicz K, Katz SD. Effects of active vs. passive recovery on work performed during serial supramaximal exercise tests. Int J Sports Med, 2004; 25(2): 109-114

Stølen T, Chamari K, Castagna C, Wisløff U. Physiology of soccer. Sports Med, 2005; 35(6): 501-536

Tanner RK, Fuller KL, Ross ML. Evaluation of three portable blood lactate analysers: Lactate Pro, Lactate Scout and Lactate Plus. Eur J Appl Physiol, 2010; 109(3): 551-559

Taoutaou Z, Granier P, Mercier B, Mercier J, Ahmaidi S, Prefaut C. Lactate kinetics during passive and partially active recovery in endurance and sprint athletes. Eur J Appl Physiol Occup Physiol, 1996; 73: $465-470$

Vilar L, Esteves P, Travassos B, Passos P, Lago-Peñas C, Davids K. Varying Numbers of Players in SmallSided Soccer Games Modifies Action Opportunities During Training. Int J Sports Sci Coach, 2014; 9(5): 1007-1018

\section{Corresponding author:}

\section{Ersan ARSLAN PhD}

Phone: +90 (484) 2231224

Fax: +90 (484) 2232038

E-mail: ersanarslan1980@hotmail.com 